\title{
A APROXIMAÇÃO SOCIOCULTURAL À MENTE, DE JAMES V. WERTSCH, E IMPLICAÇÕES PARA A EDUCAÇÃO EM CIÊNCIAS
}

\author{
Wertsch's sociocultural approach to mind \\ and its implication for Science Education
}

\author{
Alexsandro Pereira de Pereira ${ }^{1}$. Fernanda Ostermann ${ }^{2}$
}

Resumo: Este artigo apresenta uma introdução à aproximação sociocultural à mente, de James V. Wertsch. Um primeiro pressuposto da aproximação sociocultural é a noção de que a "ação mediada" é a unidade de análise. A partir dessa perspectiva, a ação humana tipicamente emprega ferramentas culturais, ou meios mediacionais, que são fornecidos por um cenário sociocultural particular. $\mathrm{O}$ uso concreto dessas ferramentas culturais envolve uma "tensão irredutível" entre agentes ativos e itens como computadores, livros, linguagem, entre outros. O objetivo do presente trabalho é apresentar a aproximação sociocultural de Wertsch como possível referencial teórico para o ensino de ciências e para as pesquisas nessa área.

Palavras-chave: Wertsch, James V. Ensino de ciências. Referencial teórico sociocultural.

\begin{abstract}
This paper presents an introduction to the sociocultural approach to mind, as outlined by James V. Wertsch. A starting point for the sociocultural approach is the claim that it takes "mediated action" as unit of analysis. From this perspective, human action typically employs cultural tools, or mediational means, that are provided by a particular sociocultural setting. The concrete use of these cultural tools involves an "irreducible tension" between active agents and items such as computers, books, language, and others. The aim of this paper is to present Wertsch's sociocultural approach as a possible theoretical framework for science teaching and for research in this area.
\end{abstract}

Keywords: Wertsch, James V. Science teaching. Sociocultural theoretical referential.

\footnotetext{
${ }^{1}$ Pós-Graduando em Ensino de Física, Universidade Federal do Rio Grande do Sul (UFRGS). Rua Coronel Lucas de Oliveira, 2304/201. Petrópolis, Porto Alegre, RS, Brasil. 90.460-001. alexsandro.pereira@ufrgs.br

${ }^{2}$ Instituto de Física, UFRGS. Porto Alegre, RS, Brasil.
} 
Pereira, A. P.; Ostermann, F.

\section{Introdução}

O quadro teórico que delinearemos no presente trabalho refere-se à contribuição intelectual de James V. Wertsch, denominada “análise sociocultural” (WERTSCH, 1998b, 2002) ou "aproximação sociocultural à mente" (WERTSCH, 1991b). Apesar de o termo "sociocultural" ser bastante difundido, entre pesquisadores, em ensino de ciências, e amplamente utilizado em estudos com uma orientação mais social, a aproximação sociocultural de Wertsch difere substancialmente de outras abordagens, sobretudo com relação à ênfase dada à noção de "ação mediada". Embora Wertsch seja frequentemente citado em estudos que utilizam como aporte teórico autores como Vygotsky e Bakhtin, sua verdadeira contribuição intelectual tem sido pouco apreciada como fundamentação teórica em pesquisas em educação em ciências, com exceção de alguns poucos trabalhos encontrados na literatura (GIORDAN, 2004, 2006; KIRCH, 2010; POLMAN; PEA, 2001). Em virtude disso, o nosso objetivo é apresentar uma introdução à aproximação sociocultural de Wertsch como um possível referencial teórico para as pesquisas em educação em ciências e para as práticas em sala de aula.

James V. Wertsch é o professor Marshall S. Snow ${ }^{3}$ de Arts \& Sciences e diretor do programa International and Area Studies da Washington University em St. Louis, Estados Unidos. Além de ocupar o cargo de professor do Departamento de Antropologia, Wertsch também é professor afiliado no Departamento de Psicologia e no Departamento de Educação dessa mesma universidade. Wertsch graduou-se bacharel em Psicologia na Universidade de Illinois em Urbana e obteve seu título de Mestre em Educação na Northwestern University. Após se doutorar em Psicologia da Educação na Universidade de Chicago em 1975, Wertsch realizou um ano de pós-doutorado em Moscou, onde trabalhou em colaboração com grandes nomes da psicologia russa, como: Luria, Leontiev, Zinchenko, entre outros. Suas pesquisas atuais investigam a formação da identidade e a memória coletiva nos Estados Unidos, assim como em países como Rússia, Estônia, República da Geórgia e outros que formavam a antiga União Soviética. Seu interesse está centrado em como as escolas e outras instituições do Estado são utilizadas para criar e manter a memória coletiva oficial.

A aproximação sociocultural de Wertsch tem suas raízes intelectuais na teoria de L. S. Vygotsky $(1987,1994)$. O termo "sociocultural” é utilizado em reconhecimento a essa herança intelectual, ainda que Vygotsky, Luria, Leontiev e outros tenham utilizado o termo sóciohistórico para descrever o método utilizado em suas pesquisas. $\mathrm{O}$ termo sociocultural, no entanto, resulta mais adequado uma vez que se refere à forma com que o legado de Vygotsky e de seus colaboradores tem sido apropriado em debates contemporâneos em ciências humanas no ocidente (WERTSCH; DEL RÍO; ALVAREZ, 1998). Wertsch (1985, 1991b) delineou a teoria de Vygotsky a partir de três temas gerais que estão presentes em todas as suas obras: (a) a confiança no método genético ou evolutivo; (b) a afirmação de que as funções mentais superiores no indivíduo derivam da vida social; (c) a afirmação de que a ação humana, tanto no plano individual como no social, é mediada por instrumentos e signos. De acordo com Wertsch (1996), os estudos de tradição vygotskyana conduzidos no ocidente têm-se centrado,

\footnotetext{
${ }^{3}$ The Marchall S. Snow professoré uma cátedra da Washington University em honra a Marschall S. Snow (1842-1916),
} reitor da faculdade de Arts \& Sciences por quase quarenta anos. 
A aproximação sociocultural à mente ...

em grande medida, no segundo desses três temas, especialmente no modo como ele se relaciona com a noção de zona de desenvolvimento proximal (Vygotsky, 1994). A aproximação sociocultural de Wertsch (1991b), por sua vez, desloca o foco das origens sociais das funções mentais superiores para o terceiro tema relativo à mediação. Segundo Wertsch (1985), a mediação de instrumentos e signos é analiticamente mais interessante porque fornece a chave para se compreenderem as mudanças quantitativas e qualitativas no desenvolvimento, assim como a transição das formas de funcionamento interpsicológico em intrapsicológico.

Ao explicar e estender a teoria de Vygotsky, Wertsch recorreu às ideias de diversos outros teóricos, em especial, aos estudos de Mikhail M. Bakhtin $(1981,1986)$ sobre translinguística. Wertsch utilizou as noções de "gêneros discursivos", definidos como tipos de enunciados produzidos em situações típicas de comunicação verbal, e de "linguagens sociais", relativas aos tipos de falante (WERTSCH, 1991b). Ele também fez uso da noção de "voz", definida como o ponto de vista ou a perspectiva geral adotada pelo falante (WERTSCH, 2002). Além das ideias de Bakhtin, Wertsch também se apoiou firmemente nas ideias de Kenneth Burke (1969) sobre o dramatismo, especialmente no que se refere às múltiplas perspectivas da ação humana.

\section{O papel da ação na aproximação sociocultural}

De acordo com Wertsch (1991b), o objetivo da aproximação sociocultural à mente consiste em elaborar uma explicação dos processos mentais humanos que reconheça a relação entre esses processos e o contexto cultural, histórico e institucional no qual eles ocorrem. Essa relação entre os processos mentais e o contexto sociocultural levanta uma série de questões acerca de alguns pressupostos de fundo (WERTSCH, 1998a). A saber, são os processos mentais que servem como ponto de partida para o estudo dos cenários socioculturais ou seria o contrário? A resposta a essa questão tem orientado, ao menos implicitamente, os trabalhos de representantes de diversas disciplinas e, conforme Wertsch (1998a, 1998b) tem alertado, essa pode não ser necessariamente a formulação mais adequada.

Segundo Wertsch (1985), o individualismo metodológico que tem dominado as pesquisas em psicologia, sobretudo nos Estados Unidos, tem como pressuposto a crença de que os fenômenos sociais e culturais poderão ser reduzidos a processos psicológicos quando os psicólogos chegarem a uma abordagem mais poderosa. O reducionismo social adotado em sociologia e ciências sociais, por outro lado, pressupõe que os processos psicológicos podem ser explicados com base em fatos sociais. Essa formulação em termos de "extremos opostos" tem caracterizado o que Cole e Wertsch (1996) referiram-se como "antinomia indivíduo-sociedade". Essa antinomia tende a estruturar o debate de tal modo que obriga os pesquisadores a adotarem uma única posição e a negarem a outra totalmente. Essa atitude, no entanto, recai sobre o fato de que há pouca fundamentação para decidir entre uma alternativa ou outra. Qualquer escolha, nesse caso, se deve muito mais a preferências pessoais ou a filiações disciplinares do que a algum tipo de critério racional.

Para evitar as armadilhas impostas pela antinomia indivíduo-sociedade, Wertsch (1998b) sugeriu que os termos "processos mentais" e "contexto sociocultural" fossem pensados não como "entidades reais" que possuem algum tipo de existência independente, mas sim como "momentos" ou "elementos" de uma unidade de análise mais inclusa, que seja capaz de des- 
Pereira, A. P.; Ostermann, F.

crever o modo como essas forças entram em contato dinâmico. Assim, um dos pressupostos fundamentais da aproximação sociocultural que Wertsch propõe consiste na afirmação de que o que deve ser descrito e explicado é a "ação" humana (WERTSCH, 1991b). Isso implica considerar aspectos do contexto sociocultural em que os processos psicológicos têm lugar. É importante destacar o fato de que dar primazia analítica à ação humana não significa explicar o que ocorre "dentro da cabeça" do indivíduo enquanto o mesmo realiza a ação. O foco está na ação em si e em todos os aspectos nela envolvidos. Isto não quer dizer que a ação humana não envolva uma dimensão psicológica individual. Ela certamente envolve. A questão é que isso deve ser pensado como um "momento" da ação, e não como um processo separado ou como uma entidade que, de alguma forma, existe em isolamento. Da forma definida por Wertsch (1998b), a ação pode ser externa ou interna e pode ser conduzida tanto por grupos (pequenos ou grandes) como por indivíduos. Esse enfoque leva a uma revisão da tarefa da aproximação sociocultural, afirmando que seu objetivo é explicar a relação entre a ação humana, de um lado, e o contexto cultural, institucional e histórico na qual essa ação ocorre, de outro.

\section{Ação mediada: uma tensão irredutível}

Uma forma de ação humana de particular interesse para a aproximação sociocultural delineada por Wertsch (1991b) é a "ação mediada". Ela consiste na unidade de análise mais adequada para o estudo do funcionamento humano (WERTSCH, 1991b, 1998a, 1998b, 2002). Isso porque a ação humana, incluindo a ação mental, tipicamente emprega "meios mediacionais", ou "ferramentas culturais", que estão disponíveis em um cenário sociocultural particular. Tais ferramentas culturais, como a linguagem e os instrumentos de trabalho, moldam a ação humana de maneira essencial. E devido ao fato de que essas ferramentas são fornecidas por um cenário sociocultural particular, a ação humana é inerentemente "situada" em um contexto cultural, histórico e institucional.

A ação mediada é caracterizada por uma "tensão irredutível" entre os agentes e as ferramentas culturais que eles empregam. Essa formulação está no núcleo da aproximação sociocultural (WERTSCH, 1998b) e nos obriga a ir além do agente individual para explicar as forças que configuram a ação humana. Isto não quer dizer que as ferramentas culturais causam a ação de alguma forma mecânica. Dentro delas mesmas, as ferramentas culturais são incapazes de operar. Somente em conjunto os agentes e as ferramentas culturais podem causar impacto. Mesmo que seja possível, e até mesmo útil, fazer uma distinção analítica entre os agentes e os meios mediacionais que eles empregam, a relação existente entre eles resulta tão fundamental que é mais adequado falar de "individuos-atuando-com-ferramentas-culturais" do que simplesmente falar de indivíduos. Essa descrição permite formular uma resposta mais adequada a questão "Quem está realizando a ação?”. Ou no caso do discurso, "Quem está falando?”.

Para ilustrar a afirmação acima, considere um exemplo relativo à memória envolvendo o uso de uma ferramenta cultural que só surgiu na sua forma atual nos últimos anos: a internet. Um professor de física decide indicar um livro sobre a teoria da relatividade a um de seus alunos. No entanto, ele não consegue lembrar do título do livro, nem do nome do autor em questão. Para resolver esse problema, ele vai até a sala dos professores, utiliza um dos computadores da escola para entrar em um site de busca da internet e digita as seguintes 
A aproximação sociocultural à mente ...

palavras-chave: livro; relatividade. A seguir, uma lista de sites de vendas aparece na tela do computador de modo que ele pode consultar um catálogo eletrônico e verificar os títulos à venda até reconhecer aquele que ele estava tentando lembrar. Uma questão fundamental, do ponto de vista da aproximação sociocultural, é a seguinte: quem lembrou? À primeira vista, a resposta parece ser "o professor", uma vez que um agente ativo precisou estar envolvido para conduzir a busca na internet. No entanto, o professor, ao menos naquele momento, não foi capaz de lembrar sozinho (isto é, sem a ajuda do site de busca da internet) o título do livro e o nome do autor em questão. Tal observação parece sugerir que talvez a "internet" deva receber os créditos pela lembrança. Mas a internet, por si só, é incapaz de fornecer espontaneamente as informações que o professor estava tentando lembrar. Do ponto de vista da ação mediada, ambos (agente e ferramenta cultural) estavam envolvidos num sistema de memória distribuída, de modo que a resposta mais adequada à questão formulada acima é: o professor atuando junto com o site de busca da internet.

Outro exemplo, relativo ao ensino de matemática básica, pode ilustrar a tensão irredutível entre agentes e ferramentas culturais. Um estudante é solicitado a multiplicar 484 por 22. Após realizar a multiplicação, ele encontra corretamente o resultado 10.648. Para justificar sua resposta, o estudante mostra, para o professor, o seu cálculo, realizado da seguinte maneira:

$$
\begin{array}{r}
484 \\
\times 22 \\
\hline 968 \\
+968- \\
\hline 10.648
\end{array}
$$

Uma questão pertinente, nesse caso, é: foi realmente o estudante (isto é, o agente isolado) quem realizou a multiplicação? Para esclarecer esse ponto, considere que o mesmo estudante seja solicitado a multiplicar 484 por 22 sem utilizar a disposição vertical dos números (um número sobre o outro). Tal operação seria muito mais difícil - e, dependendo dos números envolvidos, até impossível - de se realizar. Isso porque a maioria das pessoas instruídas é suficientemente hábil para multiplicar 2 por 4,2 por 8 e assim por diante, mas não para multiplicar 484 por 22 diretamente. A disposição vertical dos números permite reduzir um problema complexo em uma série de operações concretas com as quais os agentes sabem lidar. Isto significa que "a organização espacial - ou sintaxe - dos números é, nesse caso, parte essencial de uma ferramenta cultural sem a qual não podemos resolver esse problema. Em um importante sentido, portanto, esta sintaxe realiza parte do pensamento" (WERTSCH, 1998b, p. 29, tradução nossa).

A partir dessa perspectiva, a mente humana é "distribuída" entre agentes e as ferramentas culturais que eles empregam. Wertsch (1991b) toma emprestado, de autores como Bateson (1972), Bruner (1998) e Geertz (1989), a noção de mente como algo que "se estende além da pele". Assim, qualquer forma de ação resulta muito difícil, senão impossível, de se realizar se nela não estiver envolvida uma poderosa ferramenta cultural e um usuário habilidoso no seu manuseio. A natureza da ferramenta cultural e o uso específico que os agentes fazem dela podem variar consideravelmente. Ainda assim, ambas as partes são necessárias para a compreensão da ação humana. 
Pereira, A. P.; Ostermann, F.

\section{Propriedades da ação mediada}

Uma importante propriedade da ação mediada deriva dos escritos de Burke (1969) acerca do propósito da ação humana e sua relação com outros quatros elementos que servem como princípios geradores de sua investigação (ato, cena, agente e agência). De acordo com esse autor, "implícito nos conceitos de ato e agente está o conceito de propósito. Do mesmo modo, está implícito na agência, visto que ferramentas e métodos servem a um propósito" (BURKE, 1969, p. 289, tradução nossa). Na perspectiva de Wertsch (1998b), a principal razão para se recorrer à noção de propósito é chamar a atenção para uma questão que tem sido pouco apreciada nos debates acadêmicos, mesmo quando noções como propósito ou objetivo são incluídas na análise: a ideia de que a ação humana serve a múltiplos objetivos simultâneos. Isto significa que a ação mediada dificilmente se organiza em torno de um objetivo único e facilmente identificável. Pelo contrário, ela costuma servir a vários propósitos, muitos dos quais podem estar em conflito um com o outro.

No caso da multiplicação, por exemplo, o objetivo de se multiplicar 484 por 22 é obter o resultado correto. Mas esse propósito imediato pode estar inserido em um quadro mais amplo, como, por exemplo, impressionar um público em particular (pais, professores e colegas) ou superar um sentimento geral de fracasso escolar. Ainda assim, esses objetivos restringem a análise porque estão centrados em um ato único e específico, e porque sugerem que os objetivos da ação tenham alguma classe de realidade psicológica para o indivíduo. No entanto, quando se considera a razão pela qual a matemática é ensinada na escola, os objetivos envolvidos vão muito além dos esforços individuais de se obter o resultado correto, e entram em cena temas que não podem ser reduzidos a processos psicológicos individuais.

Para incluir os objetivos da ação no estudo da ação mediada é necessário levar em conta o fato de que as ferramentas culturais servem a determinados propósitos. Se o professor pedisse aos seus alunos para multiplicarem 484 por 22 utilizando números romanos ao invés de números arábicos, os objetivos dos agentes entrariam em conflito com os recursos proporcionados pela ferramenta cultural utilizada, já que os propósitos originais dos números romanos não incluem a multiplicação. Na perspectiva de Wertsch (1998b), a ação mediada tem múltiplos objetivos simultâneos porque os objetivos do agente não se ajustam com precisão aos objetivos associados aos diferentes meios mediacionais. No caso específico da multiplicação, o objetivo de obter o resultado correto deve estar relacionado a aspectos concretos do contexto sociocultural em questão, como, por exemplo, o fato de a ação conduzir-se em uma situação prática do cotidiano, em uma tarefa escolar ou durante uma situação de exame.

Outra propriedade da ação mediada deriva dos escritos de Vygotsky acerca do método genético ou evolutivo (VYGOTSKY, 1994; VYGOTSKY; LURIA, 1996; WERTSCH, 1985, 1991a, 1991b). Esse método é motivado pelo pressuposto de que só é possível entender muitos aspectos da mente humana recorrendo às suas origens e às transições pelas quais ela tem passado. Ainda que Vygotsky tenha focado a maior parte de sua pesquisa empírica no desenvolvimento do indivíduo (ontogênese), o método genético é igualmente aplicável em outros domínios, tais como: a filogênese, a história sociocultural e a microgênese ${ }^{4}$ (WERTSCH, 1985).

${ }^{4} \mathrm{~A}$ microgênese refere-se à formação, a curto prazo, de determinados processos psicológicos, normalmente observados durante a realização de uma tarefa específica. 
A aproximação sociocultural à mente ...

Do ponto de vista da aproximação sociocultural, a ação humana está "situada" em um ou mais caminhos evolutivos. Essa afirmação é uma extensão da noção de que a ação humana é historicamente situada. De acordo com Wertsch (1998b), desenvolvimento é um termo que se aplica à ação mediada. Essa noção contrasta com outras abordagens que supõem que o que se desenvolve é a mente do indivíduo ou outros aspectos da ação considerados em isolamento. Entre outras coisas, isto significa que os agentes, as ferramentas culturais e a irredutível tensão entre eles têm sempre um passado peculiar e estão sempre em um constante processo de transformação.

Para ilustrar esse ponto, considere um exemplo relativo ao uso de tecnologias de informação e comunicação (TIC) nas aulas de ciências. Até poucas décadas atrás, determinados processos químicos, físicos e biológicos eram visualizados nas aulas de ciências somente através das imagens nos livros didáticos e dos desenhos esboçados, no quadro-negro, pelo professor. Atualmente, com a presença de computadores nas salas de aula e o desenvolvimento de softwares específicos para o ensino de ciências, esses mesmos processos podem ser visualizados a partir do uso de simulações computacionais, permitindo que os estudantes interajam com o sistema a ser estudado. Uma questão pertinente, nesse caso, é: o que evoluiu exatamente? A explicação do desenvolvimento das aulas de ciências não pode ter como base somente os níveis de inteligência ou habilidade dos agentes envolvidos. Os professores de ciências familiarizados com as novas tecnologias podem ter um tipo de inteligência que é muito útil e valioso no contexto da simulação computacional, mas que não atenderia às necessidades de uma sala de aula tradicional, e vice-versa.

O problema é que, ao avaliarmos indivíduos em um determinado caminho evolutivo, somos tentados fortemente a concebê-los como possuidores de algum tipo de atributo abstrato, como inteligência geral, independentemente de qualquer contexto proporcionado pela ação mediada. O que o exemplo acima sugere é que inteligência é um termo que se aplica ao "sistema" criado pela tensão irredutível entre os agentes e as ferramentas culturais. Isso não significa que não exista algo que se possa chamar de inteligência geral, que diferencie um indivíduo de outro. No entanto, do ponto de vista da aproximação sociocultural, as diferenças encontradas entre indivíduos ou grupos de indivíduos devem ser entendidas mais em termos da experiência particular dos agentes com um conjunto específico de ferramentas culturais do que em termos de capacidades gerais, independentes da ação mediada.

\section{Uma análise das ferramentas culturais}

Ao examinar as propriedades da ação mediada, Wertsch (1998b) delineou cinco formulações básicas que estão diretamente relacionadas às características das ferramentas culturais. A primeira delas é a afirmação de que as ferramentas culturais são materiais. Embora a materialidade de itens como computadores, livros e calculadoras seja bastante evidente (já que constituem objetos físicos que podemos tocar e manipular), essa mesma propriedade resulta menos óbvia quando consideramos meios mediacionais semióticos, tais como a linguagem. Embora a linguagem escrita continue existindo no tempo e no espaço, mesmo quando ela não é utilizada como ferramenta cultural (como um texto de livro guardado na estante), a linguagem falada, ao contrário, parece desaparecer no ar logo após sua produção, exceto nos raros 
casos em que a fala de alguém é gravada. A instantaneidade com que se manifesta a linguagem falada torna sua dimensão material menos perceptível, mas, nem por isso, deve-se considerála menos real. A materialidade é uma característica de todos os meios mediacionais e essa propriedade implica o fato de que as ferramentas culturais podem causar modificações nos agentes. O desenvolvimento de habilidades necessárias para lidar com as ferramentas culturais surge na medida em que os agentes atuam com as propriedades materiais dessas ferramentas.

A segunda formulação é a afirmação de que as ferramentas culturais restringem ao mesmo tempo em que possibilitam a ação. De acordo com Wertsch (1998b), os estudos em psicologia tendem a centrar-se no potencial dos meios mediacionais para facilitar a ação humana. Vygotsky $(1987,1994)$, por exemplo, descreveu o modo como o desenvolvimento da linguagem na ontogênese oferece novas possibilidades de consciência humana. As teorias sobre desenvolvimento cognitivo têm formulado seus estudos em termos de como sofisticadas formas de mediação - frequentemente descritas em termo de "representações" - possibilitam formas de operações mais complexas (WERTSCH, 1991a). Apesar da relevância desses estudos, uma análise centrada somente nos recursos que as ferramentas culturais proporcionam fornece apenas uma imagem parcial. A ideia geral é a de que, mesmo quando uma ferramenta cultural liberta os agentes de algumas limitações prévias, ela introduz outras novas que lhe são próprias. Essas novas restrições geralmente são reconhecidas em retrospecto. Por exemplo, a introdução da internet discada no contexto escolar durante a década de 1990 representou um avanço no que diz respeito ao rápido acesso à informação. Professores e estudantes passaram a dispor de textos de apoio, imagens, vídeos, simulações e outros recursos que não faziam parte do acervo da biblioteca da escola. No entanto, com o surgimento da banda-larga, na década seguinte, o acesso a esses recursos tornou-se muito mais eficiente, especialmente com relação à taxa de transferência de dados. Até o surgimento da banda-larga, a maioria dos usuários não tinha consciência das restrições associadas à internet discada. Esse exemplo mostra como as ferramentas culturais são utilizadas, de um modo geral, com pouca ou nenhuma reflexão consciente por parte dos agentes.

A terceira formulação de Wertsch (1998b) consiste na afirmação de que novas ferramentas culturais transformam a ação mediada. Essa propriedade deriva dos escritos de Vygotsky (1991) acerca do método instrumental em psicologia. Segundo Vygotsky (1991, p. 65), ao ser inserido no processo do comportamento, o instrumento psicológico altera todo o fluxo e a estrutura das funções mentais. De acordo com essa formulação, o instrumento psicológico não facilita, simplesmente, uma função mental já existente. Ao invés disso, ele causa uma transformação fundamental nessas funções (WERTSCH, 1991a). Na perspectiva de Wertsch (1998b), a introdução de uma nova ferramenta cultural na ação cria uma espécie de desequilíbrio na sua organização sistemática, que provoca mudanças no agente e na ação mediada como um todo. Isto não significa que a única forma de introduzir mudanças seja através de novas ferramentas culturais. Em muitos casos, as mudanças podem ser atribuídas a diferentes níveis de habilidade ou outros aspectos relacionados aos agentes. Ainda assim, as dinâmicas de mudança causadas pela introdução de um novo meio mediacional são, com frequência, muito poderosas e costumam passar despercebidas. Esse aspecto pode ser exemplificado pela polêmica acerca do uso de calculadoras no ensino de ciências. Muitos professores de física e matemática, por exemplo, proíbem seus alunos de utilizarem a calculadora durante os exames. Embora eles raramente formulem nesses termos, a razão pela qual o uso dessa ferramenta 
cultural é proibido pelos professores resulta do fato de que a calculadora não facilita simplesmente as operações matemáticas, mas as transforma em uma forma de ação consideravelmente diferente.

Uma quarta formulação para a aproximação sociocultural é a afirmação de que as ferramentas culturais são, com frequência, produzidas por razões outras que não a facilitação da ação. Essa afirmação contrasta com a concepção na qual os meios mediacionais surgem em respostas às necessidades dos agentes. Por exemplo, a tecnologia usada nos computadores não surgiu como consequência do avanço no campo da pesquisa em educação em ciências. Os primeiros computadores de mesa, desenvolvidos na década de 1970, foram projetados para operacionalizar o fluxo de caixa nas empresas por meio de uma planilha eletrônica. Do ponto de vista da ação mediada, a aplicação dessa tecnologia no ensino de ciências é um "efeito colateral", ou seja, um acidente que teve o potencial não antecipado de transformar a ação mediada. Em alguns casos, as ferramentas culturais são produzidas com a finalidade de obstruir o desempenho dos agentes. Para ilustrar esse aspecto, Wertsch (1991b, 1998b) apresentou um exemplo relativo ao surgimento dos teclados para processadores de texto. De acordo com o autor, o teclado universal QWERTY, encontrado atualmente em computadores, foi projetado na década de 1960 com a finalidade de reduzir a velocidade de digitação dos datilógrafos. Essa exigência surgiu em função das antigas máquinas de escrever, que travavam as teclas quando pressionadas rapidamente. Em virtude disso, as letras foram distribuídas no teclado de modo que os datilógrafos se vissem forçados a utilizar a mão esquerda durante a maior parte do tempo, além de inserir outros inconvenientes adicionais. Apesar das razões originais para se utilizar o teclado QWERTY terem desaparecido, esse modelo é o mais utilizado atualmente. Esse exemplo mostra como as forças históricas e econômicas podem estar envolvidas no processo de padronização das ferramentas culturais utilizadas.

Outra formulação para a aproximação sociocultural consiste na afirmação de que as ferramentas culturais estão associadas ao poder e à autoridade. Essa afirmação contrasta com a concepção na qual a linguagem e outros meios mediacionais constituem instrumentos neutros de pensamento e comunicação. Essa propriedade deriva dos escritos de Bakhtin (1981) sobre sua formulação acerca dos tipos de discurso "autoritário" e "internamente persuasivo". O pressuposto geral é o de que o poder e a autoridade não são atributos do indivíduo, considerado em isolamento, mas sim da tensão irredutível entre os agentes e as ferramentas culturais. Para ilustrar esse ponto, segue abaixo um exemplo sobre um episódio de ensino analisado por Wertsch (1991b), relatado por Hatano e Inagaki (1991), envolvendo alunos de terceira e quarta série de uma escola pública dos Estados Unidos. Nesse episódio, o professor suspendeu uma bola de argila em uma mola e perguntou aos alunos o que aconteceria com o sistema se ele fosse colocado dentro de um recipiente com água. Ao debater sobre o assunto, alguns alunos sustentavam que a mola deveria distender, até que Ian, um aluno da quarta série, fez o seguinte pronunciamento: "mesmo que ela [a bola] esteja presa, mesmo que você coloque espaço ao seu redor, ela subiria... é uma atmosfera diferente para mudar" (apud WERTSCH, 1991b, p. 137, tradução nossa). É interessante notar que o argumento de Ian tem pouca relação com os processos físicos ali envolvidos. Ainda assim, esse discurso teve um efeito poderoso sobre o restante do grupo, já que muitos dos alunos mudaram de opinião, concordando que a mola deveria contrair. Uma questão fundamental, nesse caso, é: qual foi a fonte de autoridade nesse contexto? Ainda que Ian gozasse de boa reputação para questões acadêmicas, ele não se limitou a esco- 
Pereira, A. P.; Ostermann, F.

lher uma alternativa, deixando que sua reputação fizesse o restante do trabalho. Pelo contrário, ele se apropriou de fragmentos do gênero discursivo da "ciência oficial" - isto é, da ciência ensinada explicitamente no currículo formal - com a finalidade de persuadir seus colegas. $\mathrm{O}$ uso da palavra "atmosfera" foi determinante nesse processo, especialmente porque nenhum outro aluno recorreu a esse termo.

\section{A relação agente-ferramenta cultural}

Para caracterizar o modo como os agentes consomem as ferramentas culturais, Wertsch (1998b) colocou a ênfase em como o uso de meios mediacionais particulares leva ao desenvolvimento de habilidades específicas, mais do que ao desenvolvimento de capacidades ou aptidões gerais. Assim, para compreender as formas de ação que um indivíduo pode realizar, é necessário examinar a história de encontros reais desse indivíduo com ferramentas culturais materiais. A análise desses encontros na ontogênese é, com frequência, formulada em termos da noção de "internalização". De acordo com Wertsch (1998b), esse termo pode ser bastante enganoso porque ele encoraja a busca de conceitos internos, regras e outras entidades psíquicas bastante suspeitas (WITTGENSTEIN, 1972), além de sugerir uma oposição entre processos externos e internos. Em função disso, Wertsch (1998b) esboçou dois significados que ele considera adequado ao termo internalização, quando aplicado à ação mediada.

Um significado possível, na perspectiva de Wertsch (1993, 1995, 1998b), é o que pode ser chamado de "domínio". A noção de domínio refere-se ao saber como utilizar uma ferramenta cultural com facilidade. Nessa perspectiva, a ênfase está em "saber como" ao invés de "saber o que" (WERTSCH, 2002). Segundo o autor, a noção de domínio possui importantes vantagens com relação à noção mais geral de internalização. Isso porque essa última evoca uma imagem na qual os processos realizados inicialmente em um plano externo passam a ser realizados em uma espécie de plano interno. Tal imagem é encorajada por análises como a de Vygotsky (1994) sobre como a ação de contar ocorre originalmente no plano externo, com a ajuda dos dedos, para, posteriormente, sumir de vista, quando o processo é internalizado. De acordo com o autor, muitas formas de ação mediada são (e devem ser) realizadas no plano externo. Por exemplo, no caso do uso de simulações computacionais no ensino de ciências, não está claro o que significa realizar esse tipo de ação em um plano interno. Mesmo no exemplo da multiplicação, é pouco provável que a operação como um todo seja completamente internalizada. Dependendo dos números envolvidos, tal operação requer uma ferramenta cultural que "realize parte do pensamento". Assim, a metáfora da internalização resulta demasiadamente forte porque implica algo que frequentemente não ocorre. A noção de domínio, por outro lado, é mais adequada, uma vez que ela é aplicável a praticamente todas as formas de ação mediada.

Um segundo significado possível para o termo internalização é a noção de "apropriação" (WERTSCH, 1998b). O termo apropriação deriva dos escritos de Bakhtin (1981) e refere-se ao processo pelo qual os agentes tomam algo emprestado de outros e o tornam próprio. Com relação à apropriação, Bakhtin (1981) afirma que nem todas as palavras se submetem a qualquer pessoa com a mesma facilidade, podendo soar estranhas na boca daqueles que as pronunciam. Isso decorre do fato de que, ao se apropriarem da palavra de outros, os 
A aproximação sociocultural à mente ...

agentes as utilizam em um novo contexto, com sua própria intenção, imprimindo seu próprio acento. De acordo com Wertsch (1998b), os comentários de Bakhtin sobre a apropriação apontam para um importante aspecto da relação agente-ferramenta cultural: essa relação sempre implica resistência de alguma natureza. É importante destacar que o domínio de uma ferramenta cultural não implica apropriação. Esses processos são distintos e, como resultado, podem ser separados empiricamente.

Para ilustrar como os agentes podem dominar uma ferramenta cultural sem, com isso, apropriar-se dela, considere um exemplo sobre um episódio de ensino narrado por Mortimer e Wertsch (2003), envolvendo estudantes de oitava série de uma escola brasileira. Nesse episódio, o professor pediu que os alunos identificassem materiais sólidos, líquidos e gasosos, com base em três critérios distintos de classificação: (a) um sensório-perceptual (sólidos são rígidos, líquidos são molhados etc.); (b) um empírico (sólidos têm forma e volume bem definidos, líquidos têm volume constante e forma variável etc.); (c) um com base no modelo de partículas (em sólidos, as partículas estão geometricamente organizadas, enquanto em líquidos e gases não). De acordo com os autores, os alunos demonstraram uma forte resistência em adotar mais de um critério para classificar os materiais durante a atividade. Isso porque, para eles, a linguagem científica deveria fornecer uma única e acurada maneira de descrever o mundo. Um segundo aspecto importante nesse episódio é a atitude de um dos estudantes, Ale, com relação ao critério de seleção baseado no modelo de partículas. Esse modelo implica pensar no vidro como um líquido devido à desorganização espacial de suas partículas. Ao comentar com um de seus colegas, Ale fez a seguinte declaração: “Aqui entre nós... Eu acho que o vidro é um sólido. Se en estou na rua, en jamais usaria particulas para definir" (apud MORTIMER; WERTSCH, 2003, p. 241, tradução nossa). O que o exemplo acima sugere é que não se trata, portanto, de afirmar que o aluno em questão não conseguiu dominar o modelo de partículas para classificar os materiais. A questão, nesse caso, é se esse modelo de partículas consiste ou não em uma ferramenta cultural com a qual os estudantes se identificam e estão dispostos a utilizar fora do contexto escolar.

\section{Kit de ferramentas e os modelos de privilegiação}

Ao lidar com a diversidade de ferramentas culturais disponíveis aos seres humanos, Wertsch (1991b) sustentou que os meios mediacionais não devem ser concebidos como um todo único e indiferenciado, mas sim como diversos itens de um "kit de ferramentas". Essa metáfora é uma extensão natural da analogia proposta por Vygotsky (1994) entre ferramentas técnicas e mediação semiótica, e permite explicar as diferenças grupais e contextuais na ação mediada em termos do ordenamento de ferramentas culturais à qual os agentes têm acesso, bem como em função dos modelos de seleção que eles utilizam para escolher uma determinada ferramenta cultural para uma ocasião específica. Assim, a ação mediada continua moldada pelos meios mediacionais, porém surgem novas questões, a saber: qual a natureza da diversidade de ferramentas culturais e por que uma ferramenta cultural, em oposição à outra, é utilizada para realizar determinada tarefa?

A questão da diversidade de ferramentas culturais disponíveis aos agentes está relacionada com a noção de "heterogeneidade", proposta por Tulviste (1991), que especifica que não 
Pereira, A. P.; Ostermann, F.

existe, no indivíduo, apenas uma forma única e homogênea de pensamento, mas sim diferentes tipos de pensamento verbal (WERTSCH, 1991b). A noção de heterogeneidade pressupõe a existência de uma variedade de formas qualitativamente diferentes de representar o mundo e atuar sobre ele. A distinção entre diferentes ferramentas culturais (ou tipos de pensamento verbal) dentro de uma linguagem natural pode ser feita com base nas noções de "gêneros discursivos" e "linguagens sociais", propostas por Bakhtin (1986). De acordo com Wertsch (1991b), essas formas de linguagem são concebidas como ferramentas culturais que organizam a ação mental e comunicativa.

Dentro da linguagem natural, os agentes da ação têm acesso a mais de uma linguagem social e um gênero discursivo. Essas formas de linguagem estão organizadas de acordo com alguma classe de hierarquia dominante que está relacionada ao poder ou à aplicabilidade dessas ferramentas. Os modelos de seleção utilizados pelos agentes para escolher uma determinada ferramenta cultural são descritos em termos da noção de "privilegiação" (WERTSCH, 1991b). A privilegiação refere-se ao fato de que uma ferramenta cultural, tal como uma linguagem social, é concebida como mais eficaz ou adequada do que outras em um determinado cenário sociocultural. Durante o processo de domínio dos modelos de privilegiação, a escolha de uma ferramenta cultural pode basear-se fortemente na orientação de outros, proporcionada através da interação social. Esses modelos têm como resultado a suposição de que determinada ferramenta cultural é a mais adequada (ou, inclusive, a única possível) em um cenário sociocultural particular, mesmo quando existem outras igualmente disponíveis.

\section{A aproximação sociocultural e a educação em ciências}

\section{A ação mediada no espaço da educação formal}

De acordo com alguns autores (LEMKE, 1990; MORTIMER; SCOT'T, 2002), o ensino de ciências é caracterizado por formas de discurso bastante padronizadas que governam a dinâmica da sala de aula. A compreensão desses discursos pode ser a chave para se entender por que algumas formas de ensino são eficazes e outras não (WERTSCH, 1998b). Uma característica importante no discurso educacional é a diferença existente entre a voz do professor e as vozes dos alunos, especialmente no que se refere às relações de poder e autoridade em sala de aula. Um resultado disso é o fato de que grande parte dos enunciados produzidos pelos professores consiste em instruções que são dirigidas aos alunos. Essas instruções nem sempre tomam a forma sintática do imperativo, podendo ser formuladas em termos de "perguntas instrucionais".

As perguntas instrucionais são aquelas cujas respostas já são conhecidas pelo professor. Elas servem para gerar uma base de enunciados reguladores que possam ser dominados pelos alunos. Assim, enunciados como "quanto vale o perímetro do triângulo acima?" ou "qual é o módulo da força resultante nesse diagrama?" ajudam a gerar o discurso necessário para resolver determinados problemas no plano social. Na medida em que os alunos interagem com os enunciados concretos do professor, eles interagem também com tipos generalizados de vozes (linguagens sociais e gêneros discursivos) e se apropriam dos mesmos. Assim, o objetivo final de se formularem perguntas instrucionais não é o de resolver problemas no plano social, 
A aproximação sociocultural à mente ...

mas sim o de organizar o funcionamento intermental de modo a fomentar a transição genética desses modelos até o funcionamento intramental ${ }^{5}$. Esse processo pode ser descrito em termos da transição da "regulação-de-outros" até a "autorregulação" (WERTSCH, 1979).

As perguntas instrucionais são frequentemente empregadas dentro de um padrão sequencial triádico, constituído de uma iniciação (I) por parte do professor, seguida de uma resposta (R) de um aluno, seguida, por sua vez, de uma avaliação (A) do professor (MEHAN, 1979). Esse padrão seqüencial I-R-A garante ao professor poder e autoridade sobre o discurso, mantendo o controle das atividades, mas de modo que o processo pareça interativo (LEMKE, 1990). Apesar do pouco impacto que esse gênero discursivo tem sobre a aprendizagem dos alunos (WERTSCH, 1998b), o padrão sequencial I-R-A mantém forte presença na sala de aula. Devido às exigências do contexto sociocultural em questão, configuradas por um extenso programa de conteúdos, os professores procuram manter a ordem institucional ao mesmo tempo em que tentam estimular a aprendizagem dos alunos. Assim, não se trata simplesmente do uso de uma ferramenta cultural inadequada, mas sim do fato de que os professores estão respondendo a múltiplos objetivos simultâneos. O desafio, portanto, consiste em empregar um gênero discursivo que possa responder a ambos objetivos de maneira mais eficiente.

Além das perguntas instrucionais e do padrão sequencial I-R-A, os professores enviam, durante seu discurso, fortes mensagens implícitas sugerindo quais são os gêneros discursivos mais adequados para o contexto das atividades conduzidas em sala de aula. A aparição desses gêneros, no entanto, não tem como resultado o desaparecimento de outros gêneros discursivos previamente dominados pelos estudantes. Os alunos não deixam de usar perspectivas baseados em conceitos cotidianos ou perguntas autênticas após dominarem as formas de discurso utilizadas em sala de aula. Pelo contrário, essas ferramentas culturais continuam fazendo parte do kit de ferramentas disponíveis para os alunos. Assim, o processo de socialização através do ensino de ciências não consiste em substituir um gênero discursivo por outro, mas sim em diferenciar e acrescentar gêneros discursivos, dominando as regras para o emprego de determinados gêneros em determinados contextos socioculturais.

\section{Implicações para o ensino de ciências}

As ideias de Wertsch acerca do domínio de ferramentas culturais apontam para um importante aspecto relativo à capacidade dos agentes: o de que o desenvolvimento de certas habilidades específicas surge da experiência. Essa noção contrasta com as práticas pedagógicas tradicionais, cuja principal atividade docente é a realização de aulas expositivas. Ao invés de apenas apresentar os diversos itens do kit de ferramentas da ciência e esperar que os alunos os dominem espontaneamente, o ensino de ciência deveria oferecer mais oportunidades para os alunos atuarem com essas ferramentas, seja através de debates em grupo, resolução de problemas ou atividades experimentais nos laboratórios didáticos e de informática. A sala de aula poderia ser pensada em termos de "espaço de trabalho" ao invés de ser usada como um "auditório".

\footnotetext{
${ }^{5}$ Segundo Wertsch (1985), “intermental” e "intramental” são traduções mais acuradas para os termos interpsikbicheskii e intrapsikhicheskii, respectivamente. Esses termos são tradicionalmente traduzidos, nas obras de Vygotsky, como interpsicológico e intrapsicológico.
} 
Pereira, A. P.; Ostermann, F.

A ideia de que ação mediada responde a vários propósitos e a de que ferramentas culturais restringem, ao mesmo tempo em que possibilitam a ação, é crucial para entendermos por que alguns alunos frequentemente fracassam na realização de determinadas tarefas em sala de aula. $\mathrm{Na}$ medida em que se reconhece que os instrumentos de avaliação não avaliam a inteligência geral dos alunos, mas sim as habilidades específicas no uso de determinadas ferramentas culturais, é possível refletir sobre que ferramentas culturais são mais adequadas aos alunos na realização de uma dada tarefa. O fato de que as ferramentas culturais são, com frequência, utilizadas pelos alunos com pouca ou nenhuma reflexão consciente também traz implicações para o ensino. A tomada de consciência é o recurso mais poderoso para identificar e modificar as formas de mediação que têm consequências indesejáveis para os alunos, e esse é um exercício intelectual que deveria ser fomentado pelos professores. A percepção de que novas ferramentas culturais transformam a ação mediada e o entendimento de como essas transformações ocorrem é fundamental para o processo de domínio e apropriação por parte dos estudantes. A noção de privilegiação pode também promover uma reflexão por parte dos professores acerca do poder e da autoridade inerentes ao uso de determinadas ferramentas culturais no processo educacional em um amplo sentido.

\section{Pesquisas em ensino de ciências}

Polman e Pea (2001) apresentaram uma ferramenta cultural denominada "comunicação transformativa", desenvolvida para guiar as "instruções baseadas em investigação". A comunicação transformativa consiste em uma sequência discursiva de quatro passos: (a) o estudante faz um movimento no processo de investigação guiado pelo seu conhecimento inicial; (b) o professor compreende como esse movimento pode ter implicações para o processo de investigação de maneira que o estudante não havia pretendido; (c) o professor reinterpreta o movimento do estudante e, juntos, eles elaboram novas ideias através de perguntas e sugestões; (d) o significado da ação original do estudante é transformado. Os autores analisaram quatro episódios de ensino mediados por essa ferramenta cultural. Os resultados mostraram que o uso da "comunicação transformativa" possibilitou a transformação das ações iniciais dos alunos em formas de ações mais sofisticadas de modo que professor e alunos não haviam previsto.

Giordan (2004) analisou os padrões de interação e as diferentes funções de enunciados produzidos por professores de química e alunos de Ensino Médio ao participarem de um serviço de tutoria via correio eletrônico. O pressuposto geral é de que as características da ferramenta cultural em questão moldam a interação professor-aluno de modo a gerar novos padrões de interação. Segundo o autor, a estrutura não hierarquizada do serviço de tutoria, associado ao caráter assíncrono e multifuncional das mensagens eletrônicas, deu lugar a um padrão de interação do tipo "I-R-A invertido", no qual estudantes iniciaram as trocas e utilizaram perguntas como modos de mediação para gerar novos significados sobre "química em animais" e "ligações químicas". Em outro estudo, Giordan (2006) apresentou uma breve revisão crítica acerca do uso de computadores no ensino de ciências. Ao discutir alguns resultados de pesquisas envolvendo linguagens de programação, sistemas tutoriais, simulação e animação, entre outros temas, o autor apresentou algumas recomendações para a área e chamou a 
A aproximação sociocultural à mente ...

atenção para a necessidade de se investigar o modo como o uso do computador transforma a comunicação humana.

Ao considerar os processos de identificação, resolução e redução de incertezas como formas de ação mediada na construção do conhecimento científico, Kirch (2010) comparou o discurso de pesquisadores em biomedicina com o discurso de crianças de escola elementar, submetidos a uma atividade didática de investigação. Após identificar similaridades entre os padrões de interação utilizados pelos dois grupos, o autor discutiu implicações do processo de identificação e redução de incertezas para o ensino de ciências.

\section{Considerações finais}

$\mathrm{Na}$ terminologia utilizada no presente trabalho, a aproximação sociocultural de Wertsch consiste numa ferramenta cultural poderosa para conduzir as pesquisas sobre o funcionamento mental humano. A ação mediada como unidade de análise estabelece um vínculo natural entre as configurações socioculturais e os processos mentais no indivíduo. A tensão irredutível entre agentes e meios mediacionais, situados em um cenário sociocultural particular, nos obriga a ir além do agente individual para explicar as forças que configuram a ação humana.

A perspectiva da ação mediada naturalmente tem implicações para o ensino de ciências. Aprender ciências implica várias formas de ação humana, como: observar, descrever, comparar, classificar, analisar, questionar, argumentar, planejar, avaliar, generalizar, entre outras (LEMKE, 1990). Todas essas formas de ação mediada envolvem ferramentas culturais materiais que oferecem recursos e restrições e que estão associadas ao poder e à autoridade. Todas elas respondem a múltiplos objetivos simultâneos e estão em constante processo de evolução.

A partir desta perspectiva, a pesquisa em ensino de ciências poderia se estruturar com base em algumas questões fundamentais, a saber: quais as formas de ação mediada conduzidas no âmbito do ensino de ciências? Quais são as ferramentas culturais empregadas por professores e alunos e por que essas ferramentas são utilizadas quando existem outras igualmente disponíveis? De que modo novas ferramentas culturais podem transformar as ações mediadas conduzidas no contexto da sala de aula? Essas e outras perguntas podem representar uma agenda promissora para a pesquisa em ensino de ciências. 
Pereira, A. P.; Ostermann, F.

\section{Referências}

BAKHTIN, M. M. The dialogic imagination: four essays. Austin: University of Texas Press, 1981.

. Speech genres and other late essays. Austin: University of Texas Press, 1986.

BATESON, G. Steps to an ecology of mind: a revolutionary approach to man's understanding of himself. New York: Ballantine, 1972.

BRUNER, J. Realidade mental, mundos possíveis. Porto Alegre: Artes Médicas, 1998.

BURKE, K. A grammar of motives. Berkeley: University of California Press, 1969.

COLE, M.; WERTSCH, J. V. Beyond the individual-social antinomy in discussions of Piaget and Vygotsky. Human Development, Berkeley, v. 39, n. 5, p. 250-256, 1996.

GEERTZ, C. A interpretação das culturas. Rio de Janeiro: LTC, 1989.

GIORDAN, M. Tutoring through the internet: how students and teachers interact to construct meaning. International Journal of Science Education, London, v. 26, n. 15, p. 1875-1894, 2004.

O computador na educação em ciências: breve revisão crítica acerca de algumas formas de utilização. Ciência \& Educação, Bauru, v. 11, n. 2, p. 279-304, 2006.

HATANO, G.; INAGAKI, K. Sharing cognition through collective comprehension activity. In: RESNICK, L. B.; LEVINE, J. M.; TEASLEY, S. D. (Org.). Perspectives on socially shared cognition. Washington: American Psychological Association, 1991. p. 331-348.

$\mathrm{KIRCH}, \mathrm{S}$. A. Identifying and resolving uncertainty as a mediated action in science: a comparative analysis of the cultural tools used by scientists and elementary science students at work. Science Education, Hoboken, v. 94, n. 2, p. 308-335, 2010.

LEMKE, J. L. Talking science: language, learning and values. Norwood: Ablex, 1990.

MEHAN, H. Learning lessons. Cambridge: Harvard University Press, 1979.

MORTIMER, E. F.; SCOTT, P. Atividade discursiva nas salas de aula de ciências: uma ferramenta sociocultural para analisar e planejar o ensino. Investigações em Ensino de Ciências, Porto Alegre, v. 7, n. 3, p. 283-306, 2002.

MORTIMER, E. F.; WERTSCH, J. V. The architecture and dynamics of intersubjectivity in science classrooms. Mind, Culture and Activity, Philadelphia, v. 10, n. 3, p. 230-244, 2003.

POLMAN, J. L.; PEA, R. D. Transformative communication as cultural tool for guiding inquiry science. Science Education, Hoboken, v. 85, n. 3, p. 207-222, 2001.

TULVISTE, P. The cultural-historical development of verbal thinking. New York: Nova Science Publishers, 1991.

VYGOTSKY, L. S. Pensamento e linguagem. São Paulo: Martins Fontes, 1987. 
A aproximação sociocultural à mente ...

VYGOTSKY, L. S. El método instrumental en psicología. In: VYGOTSKY, L. S. Obras escogidas. Madrid: Visor, 1991. p. 65-70.

A formação social da mente: o desenvolvimento dos processos psicológicos superiores. 5. ed. São Paulo: Martins Fontes, 1994.

VYGOTSKY, L. S.; LURIA, A. R. Estudos sobre a história do comportamento: o macaco, o primitivo e a criança. Porto Alegre: Artes Médicas, 1996.

WERTSCH, J. V. From social interaction to higher psychological processes: a clarification and application of Vygotsky's theory. Human Development, Berkeley, v. 22, n.1, p. 1-22, 1979. Press, 1985.

Vygotsky and the social formation of mind. Cambridge: Harvard University

A sociocultural approach to socially shared cognition. In: RESNICK, L. B.; LEVINE, J. M.; TEASLEY, S. D. (Org.). Perspectives on socially shared cognition. Washington: American Psychological Association, 1991a. p. 85-100.

Voices of the mind: a sociocultural approach to mediated action. Cambridge: Harvard University Press, 1991b.

Commentary on J. A. Lawrence and J. Valsiner "Conceptual roots of internalization: from transmission to transformation". Human Development, Berkley, v. 36, n. 3, p. 168-171, 1993.

. Commentary on I. Arievitch and R. van der Veer "Furthering the internalization debate: Gal'perin's contribution". Human Development, Berkley, v. 38, n. 2, p. 127-130, 1995.

Apresentação. In: VYGOTSKY, L. S.; LURIA, A. R. Estudos sobre a história do comportamento: o macaco, o primitivo e a criança. Porto Alegre: Artes Médicas, 1996. p. $9-13$.

A necessidade da ação na pesquisa sociocultural. In: WERTSCH, J. V.; DEL RÍO, P.; ALVAREZ, A. (Org.). Estudos socioculturais da mente. Porto Alegre: Artmed, 1998a. p. $56-71$.

Mind as action. New York: Oxford University Press, 1998b.

Voices of collective remembering. New York: Cambridge University Press, 2002.

WERTSCH, J. V.; DEL RÍO, P.; ALVAREZ, A. Estudos socioculturais da mente. Porto Alegre: Artmed, 1998.

WITTGENSTEIN, L. Philosophical investigations. Oxford: Blackwell, 1972.

Artigo recebido em 18/11/2010. Aceito em 11/07/2011. 